OPEN ACCESS

Edited by:

Gary Edward McPherson, The University of Melbourne, Australia

Reviewed by:

Adina Mornell,

Hochschule für Musik und Theater

München, Germany

Karen Burland,

University of Leeds, United Kingdom

*Correspondence:

Soo Ji Kim

specare@ewha.ac.kr

Specialty section:

This article was submitted to

Performance Science,

a section of the journal

Frontiers in Psychology

Received: 04 October 2018

Accepted: 16 January 2019

Published: 18 February 2019

Citation:

Kim SJ and Yoo GE (2019) Instrument Playing as a Cognitive Intervention Task for Older Adults: A Systematic

Review and Meta-Analysis.

Front. Psychol. 10:151.

doi: 10.3389/fpsyg.2019.00151

\section{Instrument Playing as a Cognitive Intervention Task for Older Adults: A Systematic Review and Meta-Analysis}

\author{
Soo Ji Kim ${ }^{1 *}$ and Ga Eul Yoo ${ }^{2}$ \\ ${ }^{1}$ Music Therapy Education, Graduate School of Education, Ewha Womans University, Seoul, South Korea, ${ }^{2}$ Department of \\ Music Therapy, Graduate School, Ewha Womans University, Seoul, South Korea
}

The aim of this meta-analysis was to review studies that applied musical instrument playing as an intervention to improve cognitive functioning of older adults with and without cognitive impairment. English-language articles published between 1990 and 2018 were searched using electronic databases. Music therapy journals were also hand searched for relevant research. Inclusion criteria for participants were older adults, ages 60 years and older, and any clinical diagnosis of cognitive impairment had to be due to aging. Searches used combinations of the following keywords: older adults, instrument playing, and cognitive outcomes measures. A total of 10 studies that met the inclusion criteria were included in the final analysis: five studies with healthy older adults, two with older adults with mild cognitive impairment (MCl), two studies with older adults with dementia, and one study with both healthy older adults and older adults with $\mathrm{MCl}$. The results of this meta-analysis demonstrated that different types of cognitive involvement were demanded from instrument playing. Furthermore, depending on the type of involvement, a target cognitive domain was found to be differentially impacted by the instrument playing intervention. This study supports using different types of instrument playing for interventions targeting specific cognitive domains of older adults with varying levels of cognitive aging.

Keywords: instrument playing, older adults, cognitive aging, cognitive engagement, systematic review

\section{INTRODUCTION}

Age-related decline results in the general slowing of mental processing and affects the ability to control and coordinate cognitive processes (Verhaeghen et al., 2003; Fernandez-Duque and Black, 2006; Boisgonitier et al., 2013). This cognitive decline is aggravated by the onset or progression of cognitive impairment, such as dementia, and is most noticeable when it impacts active control of attentional resources that significantly affect everyday life tasks, including walking (Fernandez-Duque and Black, 2006; Sheridan and Hausdorff, 2007; Foley et al., 2011). This aggravation limits independent engagement in activities in later life, which often leads to decreased quality of life and increased individual and societal costs for healthcare. Given that cognitive decline can progress to a severe level of cognitive impairment, the development of effective interventions for improving or maintaining cognitive functioning of older adults is of particular interest to researchers, practitioners, and individuals experiencing such decline and their families (Bahar-Fuchs et al., 2013). 
Reviews of interventions for improving cognitive performance in older adults have found that these interventions range from cognitively stimulating activities to cognitive training (Martin et al., 2011; Kelly et al., 2014). Cognitive training directly and specifically targets cognitive tasks and has been documented to significantly improve various cognitive domains, such as memory, executive function, and attention/processing speed (Martin et al., 2011; Reijnders et al., 2013). However, transfer of intervention effects to everyday life activities has not been evidenced. The applicability of cognitive training to older adults with expression or progression of relatively severe cognitive impairment remains inconclusive. Compared to cognitive training, cognitive engagement interventions involve cognitively stimulating activities that may be a part of daily living, such as reading or music activities (Park et al., 2007; Martin et al., 2011). While active engagement in cognitively, physically, and socially stimulating activities of everyday life was found to reduce the risk of further cognitive impairment (Mangialasche et al., 2012), systematic analysis of how such approaches lead to expected outcomes has not been attempted.

Music activities and music-based interventions have great potential to be effectively applied to facilitate cognitive engagement of older adults. Active and intensive engagement in music activities was repeatedly reported to affect cognitive processing in later life, which is supported by musicinduced brain plasticity (Moussard et al., 2016). For older adults, maintained engagement in music activities is also predictive of their verbal and visuospatial processing (HannaPalddy and Gajewski, 2012). In terms of the potential for stimulation, music activities affect the cognitive, social, emotional, and physical domains throughout the lifespan and are easily applied to activities of everyday life (Ueda et al., 2013). As such, engagement in music activities was found to immediately stimulate cognitive performance, such as memory (Han, 2016) and reduce attentional load from intensive exercises leading to increased engagement in target activities (Kim, 2017).

Instrument playing involves motor and cognitive functions simultaneously. Instrument playing requires unimanual movement, bimanual movement, finger movement, or whole upperlimb motor movement to handle instruments (e.g., striking a drum, pressing the keys of piano, or shaking small instruments). Also, additional tasks may be integrated (e.g., remembering the rhythm to be played or learning a new way of playing the instrument). Given the increased emphasis on the interplay between cognitive and motor functioning in cognitive control in older adults (Fernandez-Duque and Black, 2006; Al-Yaha et al., 2011; Agmon et al., 2014), instrument playing involving both functions could be an effective agent for cognitive intervention to target older adults. For example, the concurrent processing of different combinations of musical elements and motor movements while switching between tasks may facilitate cognitive flexibility (Moradzadeh et al., 2015). It has been reported that engagement in intensive group instrument playing, such as in an orchestra, might address decline in inhibitory control of cognitive processing in advanced age (Vromans and Postma-Nilsenová, 2016).
Despite the potential of instrument playing for cognitive intervention, its easy accessibility to older populations, and its low demand on mental resources (Solé et al., 2014), there has not been a systematic analysis of the various types of playing tasks applied to this population. Different types and levels of tasks are presumably associated with different levels of cognitive aging and target cognitive outcomes (Li et al., 2016). Given the broad range of possible instrument playing tasks, there are calls for the systematic analysis of the factors involved, particularly as related to instrument playing as cognitive engagement for older adults. Investigation into which factors influence outcomes and how a specific aspect of instrument playing can be selected and constructed for targeted goal would delineate the implications for the specific design and implementation of an intervention based on the target individual's level of cognitive aging and unique needs.

Therefore, this study aimed to systematically review the research on instrument playing with older adults with and without cognitive impairment. The focus of this study was on analyzing the research in terms of the type of cognitive stimulation or cognitive engagement included in the instrument playing tasks and the differential effects associated with the type of cognitive domain targeted.

\section{METHODS}

\section{Search Strategy}

English-language articles published between 1990 and 2018 were searched from January through August 2018 using electronic databases, including CINAHL, Cochrane Central Register of Controlled Trials (CENTRAL), and PubMed. Keywords used in the electronic search included older adults, elderly, seniors, aging, cognitive aging, cognitive impairment, dementia, Alzheimer's disease, mild cognitive impairment (MCI) for populationspecific terms; music, music therapy, instrumental playing, musical instrument, keyboard, piano, drumming, and percussion for intervention-specific terms; and cognitive, cognition, memory, working memory, recall, executive function, visuosptial perception, verbal fluency, attention, attentional control, and processing speed for outcome-specific terms. Music therapy journals were also hand searched for relevant research published during the same time period. After initial review of titles and abstracts, duplicate studies and obviously irrelevant studies were excluded. For potentially relevant articles, full texts were retrieved and examined to ensure they met the inclusion criteria.

\section{Inclusion Criteria}

Inclusion criteria for participants were older adults, ages 60 years or older. While participants with a clinical diagnosis of cognitive impairment due to aging (i.e., dementia) were also included, individuals with comorbidity, such as other neurological or degenerative disorders, were excluded. Therefore, healthy older adults and older adults with MCI or dementia were included. With regard to type of intervention, studies were included if their intervention utilized instrument playing as a primary intervention method. Given that music intervention could involve multiple musical behaviors, such as listening and 


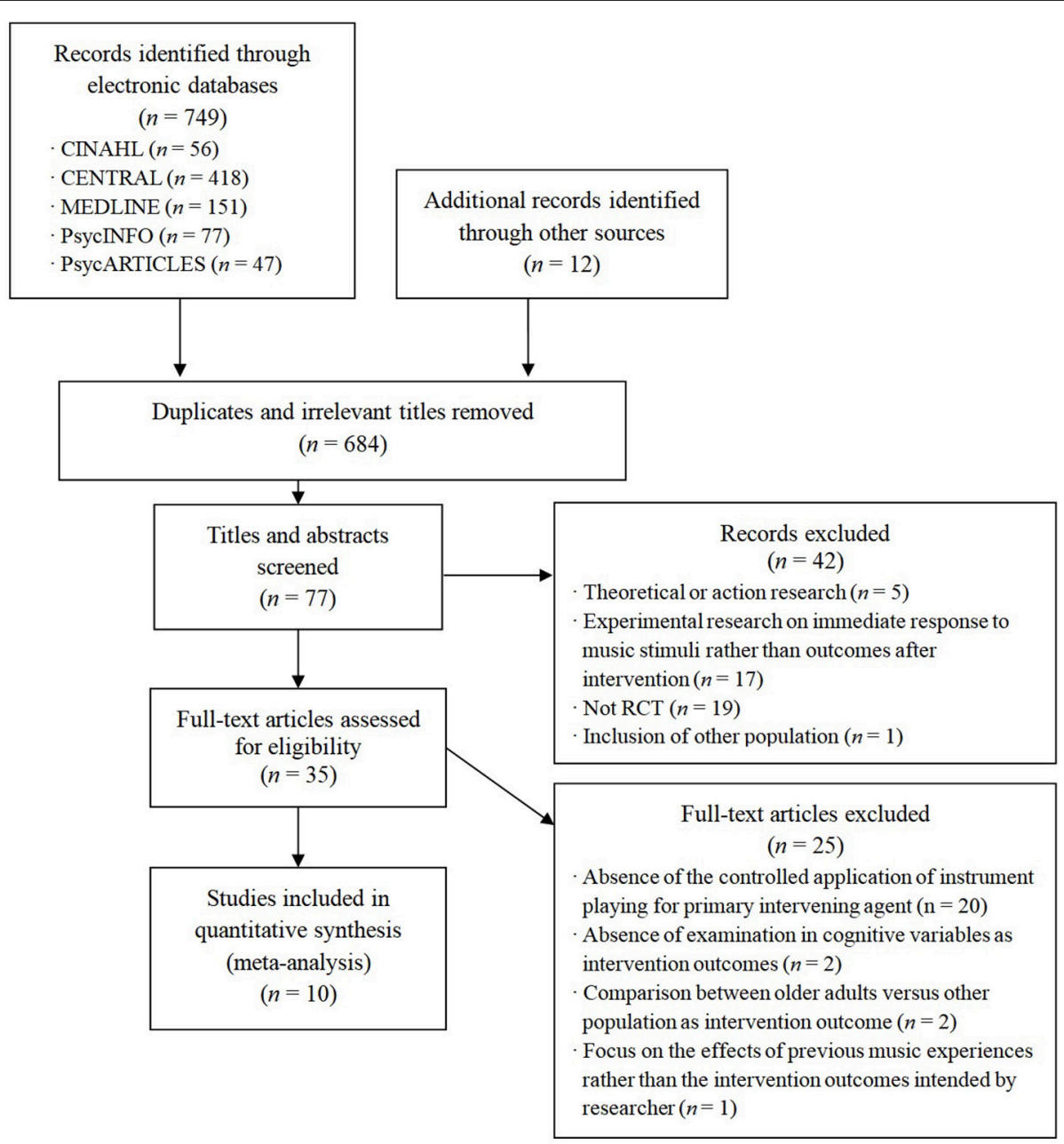

FIGURE 1 | An illustration of the number of studies identified and qualified for final analysis.

playing or singing and playing, the inclusion of another type of musical behavior did not disqualify studies. If the instrument playing was separately applied and described as a primary independent task in the intervention, the study was included. However, studies were excluded in which instrument playing was described as an auxiliary task (e.g., playing instruments while singing) or the primary task could not be identified (e.g., when the task was described as a general music activity, including both singing and instrument playing). Furthermore, in this review, studies on the effects of instrument playing compared to traditional interventions or other controlled interventions were included. To analyze the effects of instrument playing on cognitive aging, cognitive outcome measures were included, such as memory, working memory, recall, executive function, visuospatial perception, verbal fluency, attention, attentional control, and processing speed. Study designs with controlled comparison groups were eligible for inclusion in this review. Studies with randomized controlled trials, controlled clinical trials, or inclusion of a control group were included in the final analysis.

\section{Assessment of Risk of Bias in Included Studies}

Each of the included studies was assessed for its risk of bias in terms of four items: (a) random sequence generation, (b) allocation concealment, (c) blinding of outcome assessment, and (d) incomplete outcome data addressed, depending on (a) whether all participants had an equal chance of being assigned to one of the conditions, (b) whether adequate procedures to conceal group assignment were clearly reported, (c) whether outcome assessors were blinded to the information of which intervention a participant received, and (d) whether there was a report on any participants who dropped out during the study and the reason for incomplete data. The criteria used for judging each item were based on those provided in the Cochrane Handbook for Systematic Reviews of Interventions (Higgins and Green, 2011).

\section{Statistical Analysis}

Review Manager (RevMan V.5.3) was used for conducting the statistical analyses. For each outcome variable in each included 
study, standardized mean differences (SMD) were calculated with 95\% confidence intervals. For measurements that evaluated the time to complete a test and indicated more positive effects with smaller values, the mean values were multiplied by -1 to ensure that all the cases pointed in the same direction. For each of the cognitive outcome areas, the pooled estimate was analyzed using a fixed-effects model. An effect size of $0.2-0.4$ was considered a low effect size, with $0.5-0.7$ a moderate effect size, and $>0.8$ a large effect size (Cohen, 1992). The extent of heterogeneity across studies was determined by calculating the $I^{2}$ statistic. For the statistic calculating the percentage of variability in estimated effect sizes, the extent of heterogeneity was interpreted as low, medium, or high at 25,50 , and $75 \%$, respectively. To examine if the effect of instrument playing varied depending on the type of cognitive engagement, differences between effect sizes for each level of the variables were tested using Fisher's $Z$-test. $I^{2}$ statistics were conducted to measure the extent of heterogeneity within each subgroup.

\section{RESULTS}

A total of 761 articles were identified after initial database and hand searches. Duplicates and irrelevant studies were excluded, and 77 studies were retrieved for screening. Finally, 10 studies with a total of 635 participants were selected as meeting the inclusion criteria (see Figure 1). Five studies examined the effects of music intervention involving instrument playing on healthy older adults, two studies involved older adults with MCI, two studies targeted older adults with dementia, and one

TABLE 1 | Specified characteristics of included studies.

\begin{tabular}{|c|c|c|c|c|c|c|c|}
\hline \multirow[t]{3}{*}{ References } & \multicolumn{4}{|c|}{ Participant } & \multicolumn{3}{|c|}{ Intervention } \\
\hline & \multirow{2}{*}{$\begin{array}{l}\text { Research } \\
\text { design }\end{array}$} & \multirow{2}{*}{$\begin{array}{l}\text { Level of } \\
\text { cognitive } \\
\text { aging }\end{array}$} & $N$ & Mean age & \multicolumn{2}{|c|}{ Type of intervention } & \multirow{2}{*}{$\begin{array}{l}\text { Intensity } \\
\text { minutes, frequency, } \\
\text { duration }\end{array}$} \\
\hline & & & IP/Con & IP/Con & IP & Con & \\
\hline $\begin{array}{l}\text { Biasutti and } \\
\text { Mangiacotti, } 2018\end{array}$ & $\mathrm{RCT}$ & $\mathrm{H}, \mathrm{MCl}$ & $18 / 17$ & 83.39/83.76 & $\begin{array}{l}\text { Cognitive music } \\
\text { training }\end{array}$ & Gymnastic activity & 70 min, biweekly, 24 weeks \\
\hline Bugos, 2010 & Control & $\mathrm{H}$ & $24 / 22$ & $69.3 / 67.7$ & Group piano playing & Music listening & $45 \mathrm{~min}, 1 /$ week, 16 weeks \\
\hline Bugos et al., 2007 & $\mathrm{RCT}$ & $\mathrm{H}$ & $16 / 15$ & $71.4 / 69.6$ & Individual piano playing & No int. & $30 \mathrm{~min}, 1 /$ week, 6 weeks \\
\hline Chen and Pei, 2018 & $\mathrm{RCT}$ & $\mathrm{D}$ & $15 / 13$ & $77.3 / 77.3$ & $\begin{array}{l}\text { Musical dual-task } \\
\text { training }\end{array}$ & $\begin{array}{l}\text { Non-musical cognitive tasks } \\
\text { and walking exercises }\end{array}$ & $60 \mathrm{~min}, 1 /$ week, 8 weeks \\
\hline Chu et al., 2014 & $\mathrm{RCT}$ & $\mathrm{D}$ & $49 / 51$ & 82 & Group MT & Usual care & $30 \mathrm{~min}, 2 /$ week, 6 weeks \\
\hline Doi et al., 2017 & $\mathrm{RCT}$ & $\mathrm{MCl}$ & $67 / 67$ & $76.2 / 76.0$ & Cognitive music activity & Health education & 60 min, 1/week, 40 weeks \\
\hline Hars et al., 2014a & $\mathrm{RCT}$ & $\mathrm{H}$ & $23 / 29$ & $76 / 73.5$ & Multitask training & Delayed int. & $\begin{array}{l}60 \text { min, 1/week, } 45 \\
\text { weeks/year, } 4 \text { years }\end{array}$ \\
\hline Hars et al., 2014b & $\mathrm{RCT}$ & $\mathrm{H}$ & $66 / 68$ & $75 / 76$ & Multitask training & Delayed int. & 60 min, 1/week, 25 weeks \\
\hline Seinfeld et al., 2013 & СCT & $\mathrm{H}$ & $13 / 16$ & 69.3/69.6 & Group piano playing & Leisure activity & 90 min, 1/week, 4 months \\
\hline Shimizu et al., 2017 & $\mathrm{RCT}$ & $\mathrm{MCl}$ & $34 / 10$ & $74.9 / 73.3$ & Movement MT & $\begin{array}{l}\text { Single-training task } \\
\text { (exercise) }\end{array}$ & 60 min, 1/week, 12 weeks \\
\hline
\end{tabular}

IP, instrument playing; Con, control group; RCT, randomized controlled trials; H, healthy older adults; MCl, mild cognitive impairment; D, dementia; Int, intervention; MT, music therapy.

TABLE 2 | Quality assessment of included studies.

\begin{tabular}{|c|c|c|c|c|}
\hline References & $\begin{array}{c}\text { Random } \\
\text { allocation }\end{array}$ & $\begin{array}{c}\text { Allocation } \\
\text { concealment }\end{array}$ & $\begin{array}{c}\text { Blinding of outcome } \\
\text { assessors }\end{array}$ & $\begin{array}{c}\text { Incomplete } \\
\text { outcome data }\end{array}$ \\
\hline Biasutti and Mangiacotti, 2018 & Y & $\mathrm{N}$ & $\mathrm{N}$ & Y \\
\hline Bugos, 2010 & $\mathrm{~N}$ & $\mathrm{~N}$ & $\mathrm{~N}$ & $\mathrm{~N}$ \\
\hline Bugos et al., 2007 & Y & $\mathrm{N}$ & $\mathrm{N}$ & Y \\
\hline Chen and Pei, 2018 & Y & $\mathrm{N}$ & Y & Y \\
\hline Chu et al., 2014 & Y & Y & $\mathrm{N}$ & Y \\
\hline Doi et al., 2017 & Y & Y & Y & Y \\
\hline Hars et al., 2014a & Y & Y & Y & Y \\
\hline Hars et al., 2014b & Y & Y & Y & Y \\
\hline Seinfeld et al., 2013 & $\mathrm{~N}$ & $\mathrm{~N}$ & $\mathrm{~N}$ & Y \\
\hline Shimizu et al., 2017 & $\mathrm{~N}$ & $\mathrm{~N}$ & Y & Y \\
\hline
\end{tabular}

Y, Yes; N, No. 
study targeted both healthy older adults and older adults with MCI. More detailed descriptive characteristics of each study are displayed in Table 1. In terms of the quality of the included studies, seven studies (70\%) randomly assigned participants either to the intervention group that included instrument playing or the control group. Four studies reported that they appropriately concealed group allocation, and five studies stated that the assessors were blind to the group allocation. Meanwhile, $90 \%$ of the included studies reported how many data were missing and how they dealt with such missing data (see Table 2).

The instrument playing task in each study was analyzed in terms of the type of instrument playing and the subcomponents of the instrument playing task (see Table 3). The type of instrument playing included the following: instrumental improvisation, piano instruction, percussion while memorizing rhythms or reading music scores, group instrument playing in a specified rhythm or at specified timing, and instrument playing while walking. Among the included studies, five studies included the instrument playing task exclusively, while the other five studies involved instrument playing in parallel with another task.
All five studies involving another music task used instrument playing and singing tasks independently but gave them equal importance. In analyzing the subcomponents of the instrument playing tasks in the included studies, instrumental improvisation included a cognitive component in creating rhythms. Playing only to a specified timing or reading specifically designed music scores (e.g., color-coded scores) were required in other types of rhythm playing or in playing percussion. Piano playing tasks involved memorizing rhythms, reading musical notation, and learning music theory. Multitask training consisted of concurrent motor (i.e., walking or specified body movements) and cognitive components (i.e., changing movement in response to changes in music or playing the held instrument only to the specified timing).

The included studies involved playing tasks that were categorized as either immediate engagement or sustained engagement. Given that all of the tasks required novel and challenging activities and accordingly demanded the processing of new knowledge (rather than involving familiar tasks that could be performed based on existing knowledge), they were classified

TABLE 3 | Analysis of the components of cognitive stimulation.

\begin{tabular}{|c|c|c|c|c|c|c|c|}
\hline \multirow[t]{2}{*}{ References } & \multirow{2}{*}{$\begin{array}{l}\text { Type of } \\
\text { application } \\
\text { of IP tasks }\end{array}$} & \multirow{2}{*}{$\begin{array}{c}\text { Type of } \\
\text { parallel } \\
\text { music task }\end{array}$} & \multirow[t]{2}{*}{ Type of IP task } & \multirow[t]{2}{*}{ Instruments } & \multicolumn{3}{|c|}{ Subcomponents of IP tasks } \\
\hline & & & & & Motor & Motor & Cognitive \\
\hline $\begin{array}{l}\text { Biasutti and } \\
\text { Mangiacotti, } 2018\end{array}$ & $\mathrm{P}$ & S & $\begin{array}{l}\text { Instrumental } \\
\text { improvisation }\end{array}$ & $\begin{array}{l}\text { Percussion instruments } \\
\text { (NS) }\end{array}$ & Handling instruments & - & Creating rhythms \\
\hline Bugos, 2010 & $E$ & NA & Group piano playing & Piano & Finger key-pressing & - & $\begin{array}{l}\text { Reading musical notation and } \\
\text { learning music theories }\end{array}$ \\
\hline Bugos et al., 2007 & $E$ & NA & $\begin{array}{l}\text { Individualized piano } \\
\text { playing }\end{array}$ & Piano & Finger key-pressing & - & $\begin{array}{l}\text { Reading musical notation and } \\
\text { learning music theories }\end{array}$ \\
\hline $\begin{array}{l}\text { Chen and Pei, } \\
2018\end{array}$ & $P$ & S & $\begin{array}{l}\text { Musical dual-task } \\
\text { training }\end{array}$ & Percussion instruments & Handling instrument & Walking & $\begin{array}{l}\text { Maintaining a steady beat and } \\
\text { playing only for a certain section } \\
\text { of a song }\end{array}$ \\
\hline Chu et al., 2014 & $P$ & S & Rhythm playing & $\begin{array}{l}\text { Triangles, clappers, } \\
\text { maracas, handbells, } \\
\text { tambourines, and color } \\
\text { sound bell }\end{array}$ & Handling instruments & - & $\begin{array}{l}\text { Recognizing different types of } \\
\text { music and playing in a specified } \\
\text { way (rhythm; timing) }\end{array}$ \\
\hline Doi et al., 2017 & $E$ & NA & Playing percussions & $\begin{array}{l}\text { Percussion (e.g., } \\
\text { conga) }\end{array}$ & Handling instruments & - & $\begin{array}{l}\text { Memorizing rhythms and reading } \\
\text { music scores }\end{array}$ \\
\hline Hars et al., 2014a & $P$ & S & Multitask training & Percussion (N.S) & Handling instruments & Walking & $\begin{array}{l}\text { Changing movement in response } \\
\text { to changes in music and } \\
\text { performing the concurrent tasks } \\
\text { while walking }\end{array}$ \\
\hline Hars et al., 2014b & $P$ & S & Multitask training & NR & Handling instruments & Walking & $\begin{array}{l}\text { Changing movement in response } \\
\text { to changes in music and } \\
\text { performing the concurrent tasks } \\
\text { while walking }\end{array}$ \\
\hline $\begin{array}{l}\text { Seinfeld et al., } \\
2013\end{array}$ & $E$ & NA & Group piano playing & Piano & Finger key-pressing & - & $\begin{array}{l}\text { Reading musical notation and } \\
\text { learning music theories }\end{array}$ \\
\hline $\begin{array}{l}\text { Shimizu et al., } \\
2017\end{array}$ & $E$ & NA & $\begin{array}{l}\text { Multitask movement } \\
\text { MT }\end{array}$ & Naruko (clappers) & Handling instruments & $\begin{array}{l}\text { Specified } \\
\text { body } \\
\text { movement }\end{array}$ & Imitating movements \\
\hline
\end{tabular}

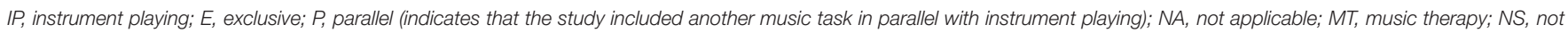
specified; NR, not reported. 
as productive engagement (Park et al., 2007). Meanwhile, depending on the period of time necessary to accomplish the instrument playing task, the tasks were subcategorized into immediate (e.g., instrument improvisation and multitasking) vs. sustained engagement (e.g., piano instruction). Furthermore, the playing tasks categorized as immediate engagement were sub-classified into tasks with additional cognitive (e.g., creating rhythms or reading color-coded scores that indicated the timing of playing) vs. additional motor tasks (e.g., walking). A summary of each category is displayed in Table 4.

In terms of target population, different types of cognitive involvement were applied (Table 5). For healthy older adults, sustained engagement was included in three studies and immediate engagement was included in three studies (one with additional cognitive tasks and two with additional motor tasks). All of the studies with participants with MCI and dementia included immediate engagement. For the two studies on older adults with dementia, one included an additional cognitive task and the other an additional motor task. For the three studies on older adults with MCI, two included cognitive tasks along with instrument playing and one included motor tasks.

The measurements used in the included studies in relation to the targeted cognitive domain are displayed in Table 6. When the target cognitive domain was categorized into general cognition, processing speed, memory, attentional control, verbal fluency, executive function, or visuospatial perception, the studies targeting healthy older adults and older adults with MCI showed similar trends in targeted subdomains and types of measurement. Meanwhile, for studies with older adults with dementia, only general cognition and attentional control were targeted. The measurements in these studies included the Mini-Mental State Examination (MMSE) and Trail Making Test-A (TMT-A), which may indicate the applicability of such measurements for individuals with relatively severe cognitive impairment.

The present analysis also investigated whether there were differences in outcomes for the different types of instrument playing tasks. For overall effects on each of seven cognitive domains, low effect sizes were obtained for general cognition $(d$

TABLE 5 | Type of cognitive involvement in the included studies depending on target population.

\begin{tabular}{lll}
\hline $\begin{array}{l}\text { Target } \\
\text { population }\end{array}$ & $\begin{array}{l}\text { Type of cognitive } \\
\text { involvement } \\
\text { (number of studies) }\end{array}$ & References \\
\hline $\begin{array}{lll}\text { Healthy older } \\
\text { adults }\end{array}$ & Immediate/cognitive (1) & Biasutti and Mangiacotti, 2018 \\
& $\begin{array}{l}\text { Immediate/motor tasks (2) } \\
\text { Sustained (3) }\end{array}$ & $\begin{array}{l}\text { Hars et al., 2014a,b } \\
\text { Bugos et al., 2007; Bugos, }\end{array}$ \\
$\begin{array}{lll}\text { Older adults with } \\
\text { dementia }\end{array}$ & $\begin{array}{l}\text { Immediate/cognitive (1) } \\
\text { Immediate/motor tasks (1) }\end{array}$ & $\begin{array}{l}\text { Chu et al., 2014 } \\
\text { Chen and Pei, 2018 }\end{array}$ \\
$\begin{array}{lll}\text { Older adults with } \\
\text { MCl }\end{array}$ & $\begin{array}{l}\text { Immediate/cognitive (2) } \\
\text { Doi et al., 2017; Biasutti and }\end{array}$ \\
& & Mangiacotti, 2018 \\
\hline
\end{tabular}

Immediate/cognitive, immediate engagement with the addition of cognitive tasks immediate/motor, immediate engagement with the addition of motor tasks; sustained, sustained engagement; $\mathrm{MCl}$, mild cognitive impairment.

TABLE 4 | Example of the category of cognitive involvement.

\begin{tabular}{|c|c|}
\hline Type & Example of instrument playing \\
\hline $\begin{array}{l}\text { Immediate engagement with } \\
\text { the addition of cognitive } \\
\text { tasks }\end{array}$ & $\begin{array}{l}\text { Striking or shaking instruments while creating a new rhythm or while } \\
\text { following the timing indicated by color-coded scores }\end{array}$ \\
\hline
\end{tabular}

Striking or shaking instruments while creating a new rhythm or while

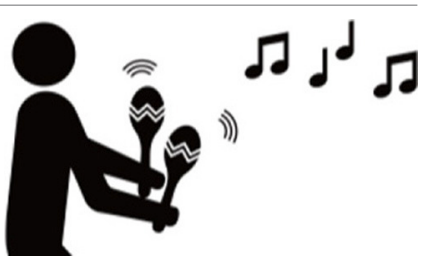

Immediate engagement with the addition of motor tasks
Striking instruments while walking and changing speed of movement in response to changes in music

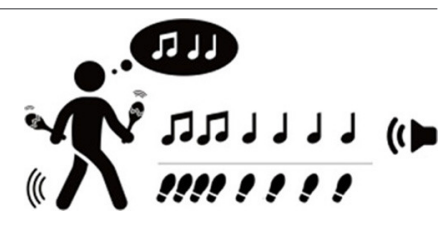

Sustained engagement

After learning music theory and score reading, playing the piano while reading a score based on memorized information 
TABLE 6 | Target cognitive domain and measurement used in the included studies.

\begin{tabular}{|c|c|c|c|}
\hline \multirow[t]{2}{*}{ Cognitive domain } & \multicolumn{3}{|c|}{ Measures used for each target population } \\
\hline & Healthy older adults & $\mathrm{MCl}$ & Dementia \\
\hline General cognition & MMSE & MMSE & MMSE \\
\hline Processing speed & AMT; PASAT & AMT & - \\
\hline Memory & DSF; DSB; Letter number; SSF; SSB & Story memory; word memory & - \\
\hline Verbal fluency & D-KEFS Verbal fluency; VFL & VFL & - \\
\hline Attentional control & TMT-A & TMT-A & TMT-A \\
\hline Executive function & FAB; Stroop; TMT-B & TMT-B & - \\
\hline Visuospatial & Block design; CDT; SDMT; TMT-A & CDT & - \\
\hline
\end{tabular}

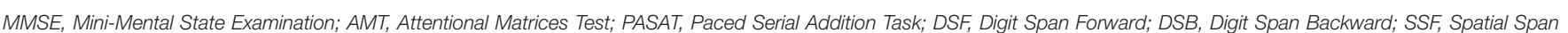

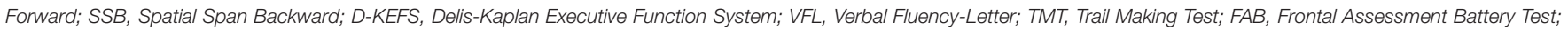
CDT, Clock Drawing Test; SDMT, Symbol Digit Modalities Test.

$=0.28)$, memory $(d=0.26)$, verbal fluency $(d=0.19)$, attentional control $(d=0.22)$, executive function $(d=0.25)$, and visuospatial perception $(d=0.19)$. A large effect size was observed for processing speed $(d=0.94)$. Substantial heterogeneity was found with processing speed, memory, and executive function (61$84 \%$ ), while low heterogeneity was found with general cognition, verbal fluency, attentional control, and visuospatial perception.

In order to see which type of cognitive domain might be addressed more effectively with which type of cognitive involvement, subgroup analysis was conducted with the moderating variable of the type of cognitive involvement [i.e., immediate engagement with the addition of cognitive tasks (immediate/cognitive), immediate engagement with the addition of motor tasks (immediate/motor), and sustained engagement (sustained)] in each cognitive domain. For general cognition, although immediate/cognitive engagement elicited a greater effect size than immediate/motor engagement, it was at a low level $(d<0.5)$. For processing speed, only instrument playing as sustained engagement was applied, and the effect size was large. For memory, sustained engagement was observed with a large effect size $(d=0.94)$, which was greater than immediate/cognitive engagement. The domains to which all three types of cognitive involvement were applied were verbal fluency, attentional control, executive function, and visuospatial perception. Except for executive function, the domains that targeted immediate/cognitive engagement led to greater effect sizes than the other two types of cognitive involvement, but the effect sizes were small $(d<0.5)$. For executive function, sustained engagement was measured with a moderate effect size $(d=0.52)$, which was greater than with the other two types of cognitive involvement (see Figures 2-4).

Finally, in terms of maintenance of intervention effects, this study analyzed how intervention outcomes were maintained after the intervention was terminated (see Table 7). Only three of 10 studies obtained follow-up data. The study by Bugos et al. (2007) demonstrated that processing speed/attention measured by the Digit Symbol Test and executive control measured by the Trail Making Test-B were enhanced at follow-up as compared to posttest, and such changes were significantly different from the no intervention group that showed a decline in such measures. However, another study (Chu et al., 2014) did not support maintenance of the intervention effects. The other study (Hars et al., 2014a) did not conduct a statistical analysis on the follow-up data for the cognitive domain, and only performed such an analysis on motor domain measures.

\section{DISCUSSION}

This study aimed to systematically review the literature on musical instrument playing for improving cognitive performance in older adults with cognitive aging. A total of 10 studies with healthy older adults, older adults with MCI, and older adults with dementia met the inclusion criteria and were included in the final analysis. The results of the current study highlight how instrument playing was applied as a cognitive engagement for enhancing or maintaining cognitive involvement in older adults with different levels of cognitive functioning.

First, instrument playing was found to involve cognitive components along with motor components. Although instrument playing basically involves motor tasks (e.g., handling objects or hand/finger movements), the instrument playing tasks in the included studies demanded additional cognitive tasks by requiring older adults to operate instruments in a specified way. Such components included sustaining attention toward external stimuli, recognizing changes in the stimuli, and selecting the expected actions in response to such input. These results indicate that instrument playing has great potential for active engagement with older adults. Compared to receptive engagement based on existing knowledge or familiar activation, productive engagement involves novel information and challenging tasks (Park et al., 2007). Given that productive engagement facilitates the cognitive process, more particularly cognitive control and executive processes, instrument playing as productive engagement may contribute to developing and expanding the resources for cognitively stimulating older adults with cognitive aging.

Furthermore, instrument playing in the literature was found to take the form of immediate engagement or sustained engagement. When immediate cognitive engagement was 


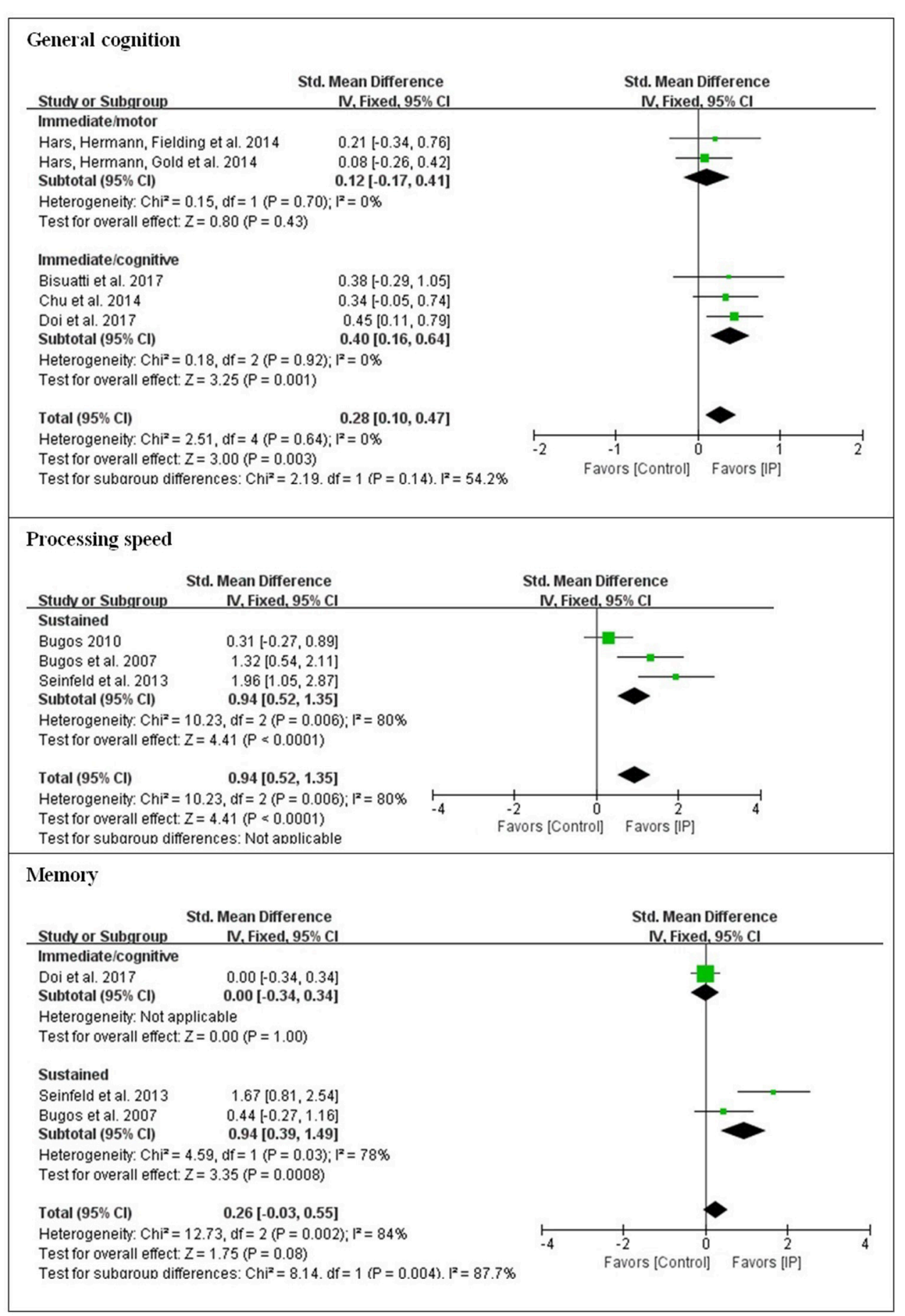

FIGURE 2 | Effect sizes of instrument playing in the domain of general cognition, processing speed, and memory depending on the type of cognitive engagement.

required from instrument playing, the participants were asked to take part in additional cognitive or motor tasks. It is noteworthy that the cognitive involvement in instrument playing differed depending on the level of cognitive aging of the participants. While instrument playing was applied to demand both immediate and sustained engagement from healthy older adults, no studies were found that required new learning over a certain period of time for older adults with cognitive impairment (i.e., MCI or dementia). Although there were not an adequate number of studies across participants with different levels of cognitive aging to reach firm conclusions, instrument playing was constructed to require a relatively limited range of cognitive involvement in older adults who experienced the onset or progression of cognitive impairment. In terms of target cognitive 


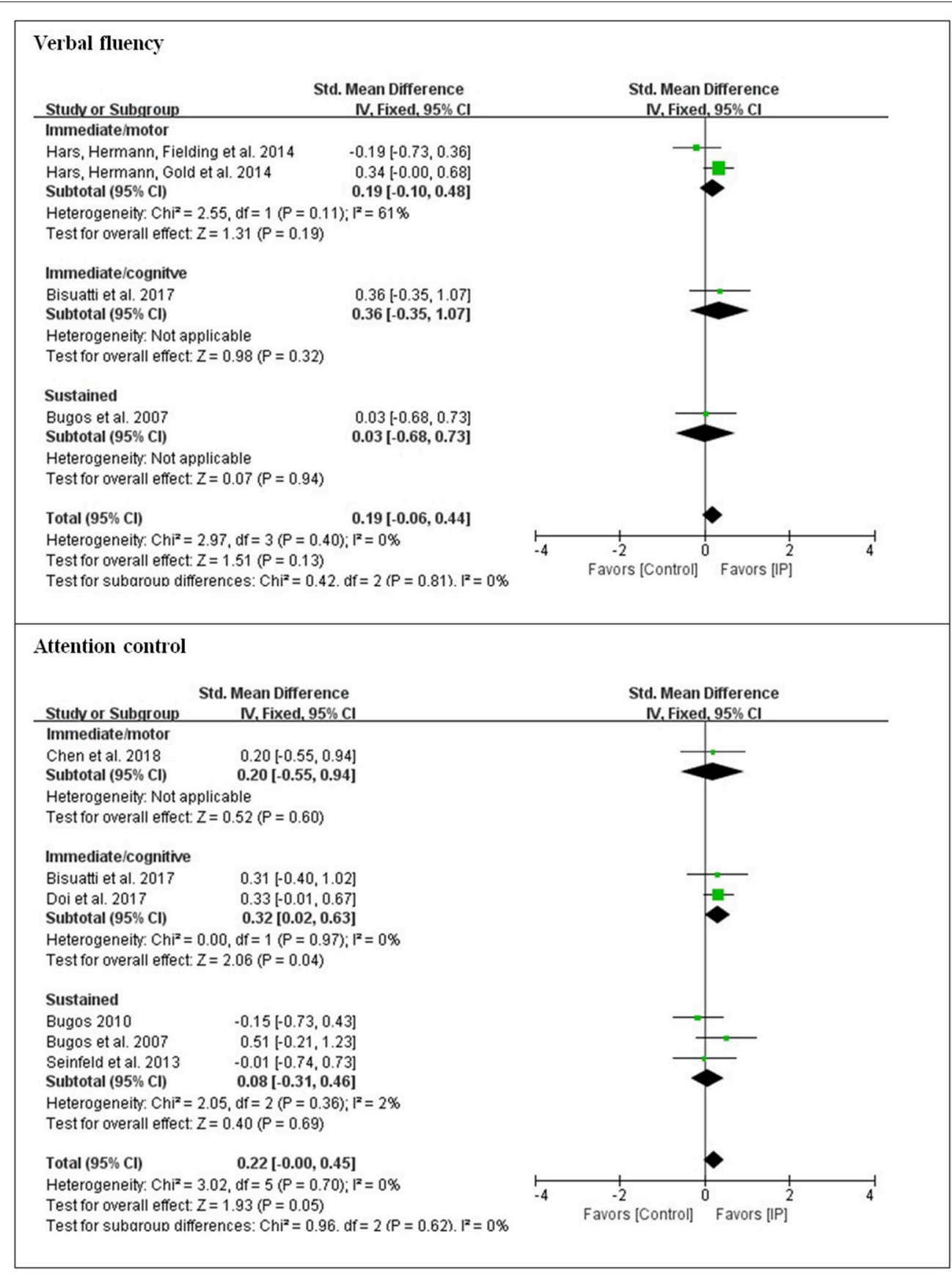

FIGURE 3 | Effect sizes of instrument playing in the domain of verbal fluency and attentional control depending on the type of cognitive engagement.

domain and outcome measurements, only general cognition and attentional control were targeted with older adults with dementia, and the measurements used only included the MMSE and TMT-A. This might be attributed to the fact that cognitive measurements of individuals with mild-to-moderate cognitive impairment have limitations.

Still, this result underscores the need for further application of instrument playing as a medium for cognitive stimulation specific to cognitive decline. It is worth noting that cognitive rehabilitation has become a critical area of focus of intervention with older adults even with moderate-to-severe dementia (Woods et al., 2012; Bahar-Fuchs et al., 2013). Moreover, the population with dementia can benefit from training that targets more complex cognitive functioning, including dual task performance as executive control of cognitive and motor tasks (Schwenk et al., 2010). Given that instrument 


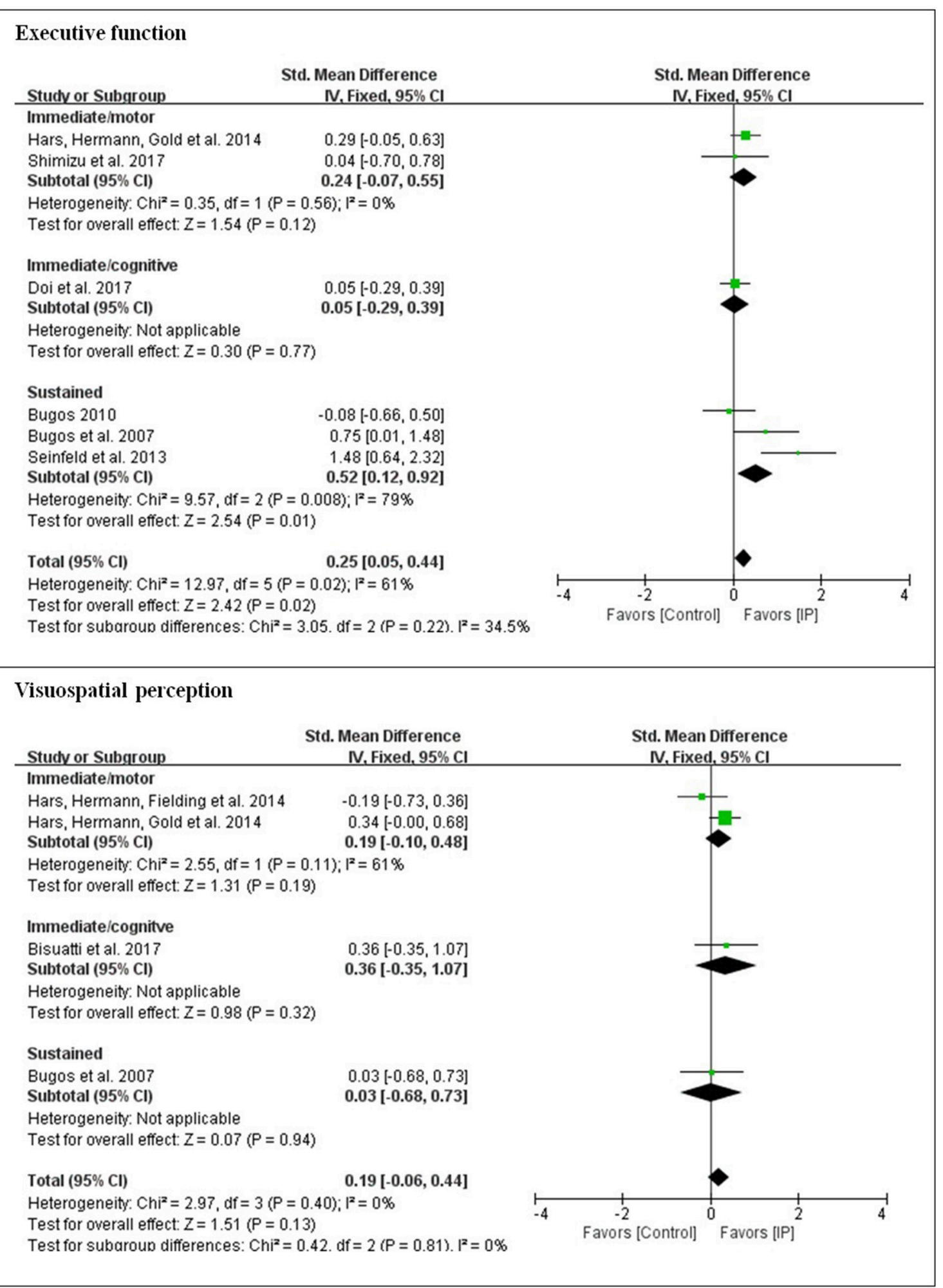

FIGURE 4 | Effect sizes of instrument playing in the domain of executive function and visuospatial perception depending on the type of cognitive engagement.

playing can be applied with a modifiable level of cognitive involvement, more diversified application of instrument playing is needed.
In this study, each type of instrument playing was found to address different cognitive domains by requiring varying levels of cognitive involvement. After intervention requiring a 
TABLE 7 | Analysis of maintenance of intervention effects in the included studies.

\begin{tabular}{|c|c|c|c|c|}
\hline References & $\begin{array}{l}\text { Time point of follow-up } \\
\text { test }\end{array}$ & $\begin{array}{l}\text { Measured cognitive } \\
\text { domain }\end{array}$ & Measurement & Result \\
\hline Chu et al., 2014 & One month after termination & General cognition & MMSE & $\begin{array}{l}\text { While Ex showed no significant decline in MMSE from } \\
\text { post-intervention to follow-up, no report on the statistical } \\
\text { analysis for Con }\end{array}$ \\
\hline Hars et al., 2014a & Three years after termination & $\begin{array}{l}\text { General cognition } \\
\text { Visuospatial perception }\end{array}$ & $\begin{array}{l}\text { MMSE } \\
\text { CDT }\end{array}$ & $\begin{array}{l}\text { No statistical analysis on the cognitive measures and } \\
\text { group comparison was conducted } \\
\text { Ex and Con showed similar results such as slight } \\
\text { decrease in MMSE and slight increase in CDT at } \\
\text { follow-up compared to post-intervention }\end{array}$ \\
\hline Bugos et al., 2007 & $\begin{array}{l}\text { Three months after } \\
\text { termination }\end{array}$ & $\begin{array}{l}\text { Processing speed/attention } \\
\text { Executive function }\end{array}$ & $\begin{array}{l}\text { Digit symbol } \\
\text { TMT-B }\end{array}$ & $\begin{array}{l}\text { Improvement in digit symbol and TMT-B from } \\
\text { post-intervention to follow-up was observed in Ex, and } \\
\text { such changes were significantly different from the Con }\end{array}$ \\
\hline
\end{tabular}

Ex, Experimental; Con, Control; MMSE, Mini-Mental State Examination; CDT, Clock Drawing Test; TMT, Trail Making Test.

new task (i.e., instrument playing) enhanced processing speed, memory, and executive function were evidenced. This supports that such a task might tap into the ability to integrate new information into the existing cognitive structure, access such information, and retrieve it from a preserved source (Hertzog et al., 2003). Repetitive utilization of cognitive resources to acquire novel information (e.g., how to read a music score to play the piano) and application of that information through task performance with progressively increased complexity (Bugos et al., 2007; Bugos, 2010) can effectively intervene in improving or maintaining those cognitive abilities. Furthermore, instrument playing that combines cognitive and motor aspects and facilitates intrinsic motivation to search for resources to accomplish novel and challenging tasks can impact the ability to regulate thoughts or behaviors while continuously tracking external stimuli and information. This result indicates that instrument playing requiring sustained engagement for new learning may effectively intervene in cognitive flexibility and executive control.

Meanwhile, instrument playing as immediate engagement along with additional cognitive tasks was found to affect general cognition, verbal fluency, attentional control, and visuospatial perception more than other types of cognitive involvement, but such effects were not at a substantial level. This indicates that this approach could stimulate cognitive performance in older adults in general, but it might not be sufficient to be transferred to other cognitive domains or performance of daily living activities. Instrument playing as immediate engagement with addition of motor tasks was not found to have large effect sizes. This might be attributed in part to the fact that the included studies measured changes in cognitive control via motor-related parameters (e.g., changes in temporal parameters of walking while walking and performing cognitive tasks concurrently). The measurements included in such studies might not directly represent changes in the involved cognitive functioning. As such, the results of this meta-analysis should be generalized with caution, since this study did not directly compare the effects of different types of instrument playing. How instrument playing can be differently constructed depending on the severity of cognitive impairment and disease progression and which outcomes its application can bring forth will need to be systematically investigated.

Finally, the results of this current review support that transfer of intervention effects to other cognitive domains is promising. As such, instrument playing has the potential to transfer to everyday life activities by cognitively stimulating and affecting lifestyle factors in older populations in their natural environment, compared to cognitive training that targets specified sets of cognitive tasks. However, follow-up data were available in only four of the 10 studies. Although a few studies demonstrated that the gained outcomes could be maintained after the intervention ended, there were not consistent and conclusive results across the studies. Accordingly, there was insufficient data to investigate the transfer and maintenance of obtained outcomes at follow-up. Further clinical research will need to address this issue by including such measures. This study supports the potential of instrument playing as a cognitively stimulating task to address the cognitive needs of older populations. However, additional studies need to be conducted that include research published in languages other than English and broader range of publications, given that intervention for aging population is of common interest worldwide and the systematic analysis of the impact of such intervention on cognitive functioning could present clinical implications.

\section{CONCLUSION}

The current study proposes how instrument playing could be constructed as a cognitively stimulating task and what could be differentially expected from a specific type of instrument playing. The results suggest that instrument playing can be differentially constructed to address the diverse needs of older adults with cognitive aging. Also, this indicates that considering the level of cognitive demand is critical for the expected intervention effects. Depending on the kinds of tasks to be targeted, clinicians may be able to design diverse levels of cognitive stimulation by determining subcomponents of the tasks. 


\section{AUTHOR CONTRIBUTIONS}

SK: research idea, research design,

data analysis, and writing; GY: data collection and analysis and writing.

\section{REFERENCES}

Agmon, M., Belza, B., Nguyen, H. Q., Logsdon, R. G., and Kelly, V. E. (2014). A systematic review of interventions conducted in clinical or community settings to improve dual task and postural control in older adults. Clin. Interv. Aging. 9, 477-492. doi: 10.2147/CIA.S54978

Al-Yaha, E., Dawes, H., Smith, L., Dennis, A., Howells, K., and Cockburn, J. (2011). Cognitive motor interference while walking: a systematic review and meta-analysis. Neurosci. Biobehav. Rev. 35, 715-728. doi: 10.1016/j.neubiorev.2010.08.008

Bahar-Fuchs, A., Clare, L., and Woods, B. (2013). Cognitive training and cognitive rehabilitation for persons with mild to moderate dementia of the Alzheimer's or vascular type: a review. Alzheimers Res. Ther. 5:35. doi: 10.1186/alzrt189

*Biasutti, M. and Mangiacotti, A. (2018). Assessing a cognitive music training for older participants: a randomised controlled trial. Int. J. Geriatr. Psychiatry 33, 271-278. doi: 10.1002/gps.4721

Boisgonitier, M., Beets, I. A., Duysens, J., Nieuwboer, A., Krampe, R. T., and Swinnen, S. P. (2013). Age-related differences in attentional cost associated with postural dual tasks: increased recruitment of generic cognitive resources in older adults. Neurosci. Biobehav. Rev. 37, 1824-1837. doi: 10.1016/j.neubiorev.2013.07.014

*Bugos, J. A. (2010). The benefits of music instruction on processing speed, verbal fluency, and cognitive control in aging. Music Educ. Res. Int. 4, 1-9.

*Bugos, J. A., Perlstein, W. M., McCrae, C. S., Brophy, T. S., and Bedenbaugh, P. H. (2007). Individualized piano instruction enhances executive functioning and working memory in older adults. Aging Ment. Health 11, 464-471. doi: 10.1080/13607860601086504

*Chen, Y. L., and Pei, Y. C. (2018). Musical dual-task training in patients with mild-to-moderate dementia: a randomized controlled trial. Neuropsychiatr. Dis. Treat. 14, 1381-1393. doi: 10.2147/NDT.S159174

*Chu, H., Yang, C. Y., Lin, Y., Ou, K. L., Lee, T. Y., O’Brien, A. P., et al. (2014). The impact of group music therapy on depression and cognition in elderly persons with dementia: a randomized controlled study. Biol. Res. Nurs. 16, 209-217. doi: $10.1177 / 1099800413485410$

Cohen, J. (1992). A power primer. Psychol. Bull. 112, 155-159. doi: 10.1037/0033-2909.112.1.155

*Doi, T., Verghese, J., Makizako, H., Tsutsumimoto, K., Hotta, R., Nakanubo, S., et al. (2017). Effects of cognitive leisure activity on cognition in mild cognitive impairment: results of a randomized controlled trial. J. Am. Med. Dir. Assoc. 18, 686-691. doi: 10.1016/j.jamda.2017.02.013

Fernandez-Duque, D., and Black, S. E. (2006). Attentional networks in normal aging and Alzheimer's disease. Neuropsychology 20, 133-143. doi: 10.1037/0894-4105.20.2.133

Foley, J. A., Kaschel, R., Logie, R. H., and Della Sala, S. (2011). Dual-task performance in Alzheimer's disease, mild cognitive impairment, and normal ageing. Arch. Clin. Neuropsychol. 26, 340-348. doi: 10.1093/arclin/acr032

Han, S. A. (2016). Song-induced autobiographical memory of patients with early Alzheimer's dementia. J. Music Hum. Behav. 12, 49-66. doi: 10.21187/jmhb.2016.13.2.49

Hanna-Palddy, B., and Gajewski, B. (2012). Recent and past musical activity predicts cognitive aging variability: direct comparison with general lifestyle activities. Front. Hum. Neurosci. 6:198. doi: 10.3389/fnhum.2012.00198

*Hars, M., Herrmann, F. R., Fielding, R. A., Reid, K. F., Rizzoli, R., and Trombetti, A. (2014a). Long-term exercise in older adults: 4-year outcomes of music-based multitask training. Calcif. Tissue. Int. 95, 393-404. doi: 10.1007/s00223-014-9907-y

\section{FUNDING}

This work was supported by the National Research Foundation of Korea Grant funded by the Korean Government (NRF2014S1A5A2A03066008).

*Hars, M., Herrmann, F. R., Gold, G., Rizzoli, R., and Trombetti, A. (2014b). Effect of music-based multitask training on cognition and mood in older adults. Age Ageing 43, 196-200. doi: 10.1093/ageing/aft163

Hertzog, C., Dixon, R. A., Hultsch, D. F., and MacDonald, S. W. (2003). Latent change models of adult cognition: are changes in processing speed and working memory associated with changes in episodic memory? Psychol. Aging 18, 755-769. doi: 10.1037/0882-7974.18.4.755

Higgins, J., and Green, S. (2011). Cochrane Handbook for Systematic Reviews of Interventions Version 5.1.0. Available online at: http://handbook.cochrane.org (Accessed October 1, 2017).

Kelly, M. E., Loughrey, D., Lawlor, B. A., Robertson, I. H., Walsh, C., and Brennan, S. (2014). The impact of cognitive training and mental stimulation on cognitive and everyday functioning of healthy older adults: a systematic review and meta-analysis. Ageing Res. Rev. 15, 28-43. doi: 10.1016/j.arr.2014.02.004

Kim, H. J. (2017). The level of fatigue and motor performance during drum playing depending on co-presence of singing tasks in patients with chronic stroke. $J$. Music Hum. Behav. 14, 71-90. doi: 10.21187/jmhb.2017.14.2.071

Li, H. C., Wang, H. H., Chous, F. H., and Chen, K. M. (2016). The effect of music therapy on cognitive functioning among older adults: a systematic review and meta-analysis. J. Am. Med. Dir. Assoc. 16, 71-77. doi: 10.1016/j.jamda.2014.10.004

Mangialasche, F., Kivipelto, M., Solomon, A., and Fratiglioni, L. (2012). Dementia prevention: current epidemiological evidence and future perspective. Alzheimers Res. Ther. 4:6. doi: 10.1186/alzrt104

Martin, M., Clare, L., Altgassen, A. M., Cameron, M. H., and Zehnder, F. (2011). Cognition-based interventions for healthy older people and people with mild cognitive impairment. Cochrane Database Syst. Rev. 19:CD006220. doi: 10.1002/14651858.CD006220.pub2

Moradzadeh, L., Blumenthal, G., and Wiseheart, M. (2015). Musical training, bilingualism, and executive function: a closer look at task switching and dual-task performance. Cogn. Sci. 39, 992-1020. doi: 10.1111/cogs.12183

Moussard, A., Bermudez, P., Alain, C., Tays, W., and Moreno, S. (2016). Life-long music practice and executive control in older adults: an event-related potential study. Brain Res. 1642, 146-153. doi: 10.1016/j.brainres.2016.03.028

Park, D. C., Gutchess, A. H., Meade, M. L., and Stine-Morrow, E. A. L. (2007). Improving cognitive function in older adults: nontraditional approaches. J. Gerontol. B Psychol. Sci. Soc. Sci. 62, 45-52. doi: 10.1093/geronb/62.special_issue_1.45

Reijnders, J., van Heugten, C., and van Boxtel, M. (2013). Cognitive interventions in healthy older adults and people with mild cognitive impairment: a systematic review. Ageing Res. Rev. 12, 263-275. doi: 10.1016/j.arr.2012. 07.003

Schwenk, M., Zieschang, T., Oster, P., and Hauer, K. (2010). Dual-task performances can be improved in patients with dementia: a randomized controlled trial. Neurology 74, 1961-1968. doi: 10.1212/WNL.0b013e3181e39696

* Seinfeld, S., Figueroa, H., Ortiz-Gil, J., and Sanchez-Vives, M. V. (2013). Effects of music learning and piano practice on cognitive function, mood and quality of life in older adults. Front. Psychol. 4:810. doi: 10.3389/fpsyg.2013.00810

Sheridan, P. L., and Hausdorff, J. M. (2007). The role of higher-level cognitive function in gait: executive dysfunction contributes to fall risk in Alzheimer's disease. Dement. Geriatr. Cogn. Disord. 24, 125-137. doi: 10.1159/0001 05126

*Shimizu, N., Umemura, T., Matsunaga, M., and Hirai, T. (2017). Effects of movement music therapy with a percussion instrument on physical and frontal lobe function in older adults with mild cognitive impairment: a randomized 
controlled trial. Aging Ment. Health 1-13. doi: 10.1080/13607863.2017.1379048. [Epub ahead of print].

Solé, C., Mercadal-Brotons, M., Galati, A., and De Castro, M. (2014). Effects of group music therapy on quality of life, affect, and participation in people with varying levels of dementia. J. Music Ther. 51, 103-125. doi: 10.1093/jmt/ thu003

Ueda, T., Suzukamo, Y., Sato, M., and Izumi, S. (2013). Effect of music therapy on behavioral and psychological symptoms of dementia: a systematic review and meta-analysis. Ageing Res. Rev. 12, 628-641. doi: 10.1016/j.arr.2013. 02.003

Verhaeghen, P., Steitz, D. W., Sliwinski, M. J., and Cerella, J. (2003). Aging and dual-task performance: a meta-analysis. Psychol. Aging 18, 443-460. doi: 10.1037/0882-7974.18.3.443

* References marked with an asterisk indicate the studies included in this
meta-analysis.
Vromans, R., and Postma-Nilsenová, M. (2016). Can musical engagement alleviate age-related decline in inhibitory control? Emotion 750, 6-36.

Woods, B., Aguirre, E., Spector, A. E., and Orrell, M. (2012). Cognitive stimulation to improve cognitive functioning in people with dementia. Cochrane Database Syst. Rev. 15:CD005562. doi: 10.1002/14651858.CD005562.pub2

Conflict of Interest Statement: The authors declare that the research was conducted in the absence of any commercial or financial relationships that could be construed as a potential conflict of interest.

Copyright (0 2019 Kim and Yoo. This is an open-access article distributed under the terms of the Creative Commons Attribution License (CC BY). The use, distribution or reproduction in other forums is permitted, provided the original author(s) and the copyright owner(s) are credited and that the original publication in this journal is cited, in accordance with accepted academic practice. No use, distribution or reproduction is permitted which does not comply with these terms. 